\title{
Protease Inhibitors Prevent Plasminogen-Mediated, But Not Pemphigus Vulgaris-Induced, Acantholysis in Human Epidermis
}

\author{
Theda Schuh', Robert Besch1, Evelyn \\ Braungart', Michael J. Flaig', Kathrin Douwes', \\ Christian A. Sander', Viktor Magdolen², \\ Christopher Probst ${ }^{3}$, Katja Wosikowski ${ }^{3}$ and \\ Klaus Degitz ${ }^{1, *}$ \\ 'Department of Dermatology, Ludwig-Maximilians \\ University, D-80337 Munich, Germany \\ 2Department of Obstetrics and Gynecology, Technical \\ University of Munich, D-81675 Munich, Germany \\ ${ }^{3}$ Wilex AG, D-81675 München, Germany \\ ${ }^{*}$ Corresponding author
}

Pemphigus is an autoimmune blistering disease of the skin and mucous membranes. It is caused by autoantibodies directed against desmosomes, which are the principal adhesion structures between epidermal keratinocytes. Binding of autoantibodies leads to the destruction of desmosomes resulting in the loss of cell-cell adhesion (acantholysis) and epidermal blisters. The plasminogen activator system has been implicated as a proteolytic effector in pemphigus. We have tested inhibitors of the plasminogen activator system with regard to their potential to prevent pemphigus-induced cutaneous pathology. In a human split skin culture system, IgG preparations of sera from pemphigus vulgaris patients caused histopathologic changes (acantholysis) similar to those observed in the original pemphigus disease. All inhibitors that were tested (active site inhibitors directed against UPA, tPA, and/or plasmin; antibodies neutralizing the enzymatic activity of uPA or tPA; substances interfering with the binding of UPA to its specific cell surface receptor uPAR) failed to prevent pemphigus vulgaris IgG-mediated acantholysis. Plasminogen-mediated acantholysis, however, was effectively antagonized by the synthetic active site serine protease inhibitor WX-UK1 or by $p$-aminomethylbenzoic acid. Our data argue against applying anti-plasminogen activator/anti-plasmin strategies in the management of pemphigus.

Key words: Acantholysis/Pemphigus/Plasminogen activator system/Protease inhibitors/Skin organ culture.
Activation of the proteolytic plasminogen activator system plays a central role for extracellular matrix degradation under various physiological and pathological conditions including blood clotting or cancer invasion (Schmitt et al., 1997; Andreasen et al., 2000; Sperl et al., 2001). In the skin, epidermal keratinocytes synthesize and secrete the urokinase-type plasminogen activator (UPA), which binds to its specific receptor (UPAR) on the keratinocyte surface. There, uPA proteolytically activates cell surfacebound plasminogen, which in turn cleaves many extracellular matrix components providing pericellular proteolysis (Kramer et al., 1995). UPA activity is controlled by the specific plasminogen activator inhibitors, PAI-1 and PAI2. Besides its importance for the reepithelialization of cutaneous wounds (Romer et al., 1996; Braungart et al., 2001), the plasminogen activator system has also been implicated in the pathophysiology of pemphigus, an autoimmune blistering disease of the skin and mucous membranes. Pemphigus is caused by autoantibodies that recognize the desmosomal proteins desmoglein 3 (pemphigus vulgaris) or desmoglein 1 (pemphigus foliaceus). Desmosomes are the principal adhesion structures between epidermal keratinocytes. Binding of desmoglein autoantibodies leads to the destruction of desmosomes, resulting in the loss of cell-cell adhesion (acantholysis), and the formation of epidermal blisters (Amagai 1996; Koch et al., 1997). While there is solid experimental evidence for autoantibodies being the primordial cause of the disease, this cannot answer all questions, e.g., why blisters develop only at certain skin areas, although autoantibodies are present within the entire skin. One attempt to account for this observation concerns the plasminogen activator system, whose upregulation has been considered as one mechanism that may subsequent to the binding of autoantibodies to desmosomes - contribute to acantholysis and blister formation. This view is supported by several observations: (i) increases of uPA (Schaefer et al., 1996) or tPA (Jensen et al., 1988; Baird et al., 1990) were detected in lesional, but not uninvolved, epidermis of pemphigus patients; (ii) in cultured keratinocytes, IgG serum fractions from patients with pemphigus vulgaris induce expression of UPA (Wilkinson et al., 1989) and uPAR (Seishima et al., 1997); (iii) pemphigus-lgG or plasminogen-induced acantholysis in skin organ cultures was inhibited by anti-uPA antibodies (Morioka et al., 1987), anti-uPAR antibodies (Xue et al., 1998), or purified PAI-2 (Hashimoto et al., 1989). 
However, the relevance of the plasminogen activator system is questioned by the observation that in neonatal mice, despite a deficiency for plasminogen activators, pemphigus IgG induced epidermal blisters (Mahoney et al., 1999).

Pemphigus is currently primarily treated with systemic glucocorticoids and other immunosuppressants. Therefore, the inhibition of plasminogen-mediated proteolysis could become a suitable complementary pharmacologic concept allowing to reduce side-effect prone immunosuppressive therapies.

In this study, we have explored the potential of various inhibitors of the plasminogen system, including specific active site inhibitors of plasminogen activators, to interfere with pemphigus-induced acantholysis in a human skin organ culture system. In this model, human skin explants are exposed to IgG preparations of sera from pemphigus patients. The resulting pathologic changes resemble those observed in the original pemphigus disease (Michel and Ko 1974; Barnett et al., 1977).

Exposure of human split skin samples to pemphigusvulgaris IgG for $24 \mathrm{~h}$ resulted in the appearance of epidermal clefts and acantholytic cells in the suprabasal epidermal layers (Figure 1A). There was also the characteristic 'tombstone' layer of basal keratinocytes adjacent to the dermo-epidermal junction, which is due to keratinocytes that remain attached to the basal membrane via hemidesmosomes. Hemidesmosomes, as opposed to desmosomes, are not recognized and damaged by pemphigus autoantibodies. As a control, incubation of skin explants with an IgG fraction of serum from a healthy donor did not affect the integrity of the skin explant (Figure 1B). This excludes the presence of relevant amounts of plasminogen/plasmin or other proteolytically active substances in the IgG preparations and suggests that the observed acantholysis was an autoantibody-specific effect.

In order to delineate the contribution of the plasminogen activator system to pemphigus-associated acantholysis and to explore the preventive potential of interference with the plasminogen activator system, a panel of broad or specific inhibitors of the plasminogen activator system (Table 1) was added to the explant culture medium prior to exposure to pemphigus vulgaris IgG, and their effects on acantholysis was monitored histologically. The inhibitors were added to the skin explant culture medium at toxicologically tolerable and therapeutically feasible concentrations $150 \mathrm{~min}$ prior to pemphigus vulgaris IgG (24 h incubation). The synthetic active site inhibitors (for details see Table 1) WX-UK1 (10-20 $\mu \mathrm{M})$ and WX-293 (50-100 $\mu \mathrm{M})$, or $p$-aminomethylbenzoic acid $(1 \mu \mathrm{g} / \mathrm{ml}, 6.62 \mu \mathrm{M})$ did not affect pemphigus vulgaris IgG-mediated acantholysis. Furthermore, the application of an anti-uPA mAb (inhibiting enzymatic activity of uPA, $100 \mu \mathrm{g} / \mathrm{ml}$ ), an anti-uPAR mAb (blocking uPA/uPAR-interaction; $100 \mu \mathrm{g} / \mathrm{ml}$ ), or a cyclic peptide interfering with uPA/uPAR-interaction
A

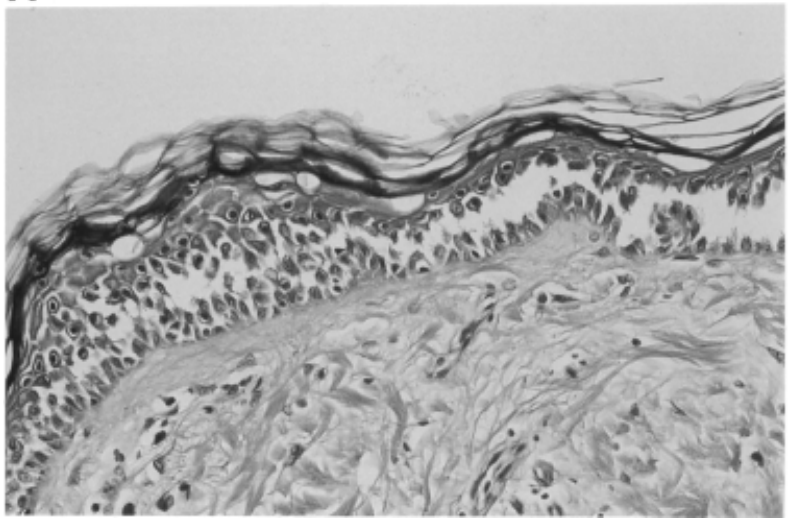

B

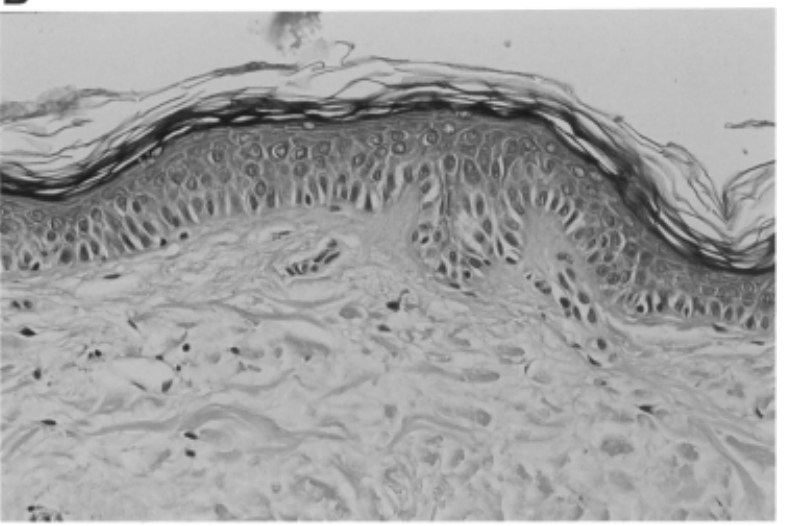

Fig. 1 Pemphigus IgG Causes Epidermal Acantholysis in Human Split Skin Explants.

Explants of normal human skin were generated from $0.4 \mathrm{~mm}$ thick split skin produced and left over during skin transplantation procedures. Informed consent had been obtained from all patients prior to surgical removal. Explants were trimmed to $4 \times 4 \mathrm{~mm}$ pieces and placed epidermis side up in Dulbecco's modified Eagle medium supplemented with 15 mm HEPES (Sigma, Deisenhofen, Germany), $2 \mathrm{~mm}$ L-glutamine, $100 \mathrm{U} / \mathrm{ml}$ penicillin, $100 \mu \mathrm{g} / \mathrm{ml}$ streptomycin, $1 \mu \mathrm{g} / \mathrm{ml}$ amphotericin B (all from Life Technologies, Karlsruhe, Germany) in the absence of serum. Incubation was carried out (A) with pemphigus vulgaris lgG (237 $\mu \mathrm{g} / \mathrm{ml})$ or (B) with lgG (237 $\mu \mathrm{g} / \mathrm{ml}) \mathrm{from}$ a healthy control donor for $24 \mathrm{~h}$ at $37^{\circ} \mathrm{C}$ and $5 \% \mathrm{CO}_{2}$. Explants were then harvested and processed for histologic examination (formalin fixation, paraffin embedement, and hematoxylin-eosin staining). Histologic specimens were viewed at an Axioskop 2 microscope (Carl Zeiss, Jena, Germany) and photographed. (A) and (B) are hematoxylin- and eosin-stains. IgG fractions were prepared using CaCl2/dextrane sulfate precipitation, and sequential column affinity chromatography with lysine-Sepharose and protein A Sepharose columns. Chromatography fractions containing IgG were pooled, dialyzed against phosphate-buffered saline, and sterile filtered. IgG was from patients with pemphigus vulgaris, none of which had received specific immunosuppressive therapy prior to serum collection. In the experiment displayed IgG from a pemphigus vulgaris patient experiencing a disease flare-up was used. By indirect immunofluorescence, his serum pemphigus antibody titer was 160 (monkey esophagus as substrate). As a control, serum was also collected from normal donors, and IgG was prepared in an identical manner along with pemphigus vulgaris sera. One representative of three independent experiments is shown. Similar results were obtained with lgG-preparations from two additional donors (data not shown). 
Table 1 Inhibitors of Plasminogen Activation.

\begin{tabular}{|c|c|}
\hline WX-UK1 & $\begin{array}{l}\text { 3-Amidinophenylalanine-based serine protease inhibitor (Stürzebecher et al., 1999); } \\
K_{\mathrm{i}}[\mathrm{uPA}]: 0.41 \mu \mathrm{M} ; K_{\mathrm{i}}[\mathrm{tPA}]: 4.9 \mu \mathrm{M} ; K_{\mathrm{i}} \text { [plasmin]: } 0.39 \mu \mathrm{M}\end{array}$ \\
\hline WX-UK1-D & Inactive D-enantiomer of WX-UK1 \\
\hline WX-293 & $\begin{array}{l}\text { Phenylguanidine-based inhibitor specific for uPA (Sperl et al., 2000); } \\
K_{\mathrm{i}}[\mathrm{UPA}]: 2.12 \mu \mathrm{M} ; K_{\mathrm{i}}[\mathrm{tPA}]:>1000 \mu \mathrm{M} ; K_{\mathrm{i}} \text { [plasmin]: > } 1000 \mu \mathrm{M}\end{array}$ \\
\hline $\begin{array}{l}\text { p-Aminomethylbenzoic } \\
\text { acid }\end{array}$ & $\begin{array}{l}\text { Synthetic lysine analog (Sigma, Steinheim, Germany); suppresses plasminogen conversion to plasmin } \\
\text { (Dobrev et al., 1996) }\end{array}$ \\
\hline tPAstop & $\begin{array}{l}\text { Synthetic selective tPA inhibitor (American Diagnostica, Pfungstadt, Germany); } \\
K_{\mathrm{i}}[\mathrm{tPA}]: 0.082 \mu \mathrm{M} ; K_{\mathrm{i}}[\mathrm{uPA}]: 3.4 \mu \mathrm{M} ; K_{\mathrm{i}}[\text { plasmin]: } 6.4 \mu \mathrm{M}\end{array}$ \\
\hline WX-374 & $\begin{array}{l}\text { Cyclic peptide cyclo }{ }^{21,29}\left[\mathrm{D}-\mathrm{Cys}^{21} \mathrm{Orn}^{23} \mathrm{Cys}^{29}\right]-\mathrm{uPA}_{21-30} \text {; inhibits uPA/uPAR-interaction with an } \mathrm{IC}_{50} \text { of } 280 \mathrm{~nm} \\
\text { (derived from cyclo }{ }^{21,29}\left[\mathrm{D}-\mathrm{Cys}^{21} \mathrm{Cys}^{29}\right]-\mathrm{uPA}_{21-30} \text { (Guthaus et al., 2002) }\end{array}$ \\
\hline Anti-uPAR & $\begin{array}{l}\text { Mouse IgG1 monoclonal (mAb) IIIF10 directed to human uPAR; blocks uPA/uPAR-interaction (Luther et al., } \\
\text { 1997) }\end{array}$ \\
\hline Anti-uPA & Mouse lgG1 mAb directed against human uPA; neutralizes enzymatic activity of uPA (American Diagnostica) \\
\hline Anti-tPA & $\begin{array}{l}\text { Goat polyclonal antibodies directed to human tPA; neutralizes enzymatic activity of tPA (American } \\
\text { Diagnostica) }\end{array}$ \\
\hline
\end{tabular}

A

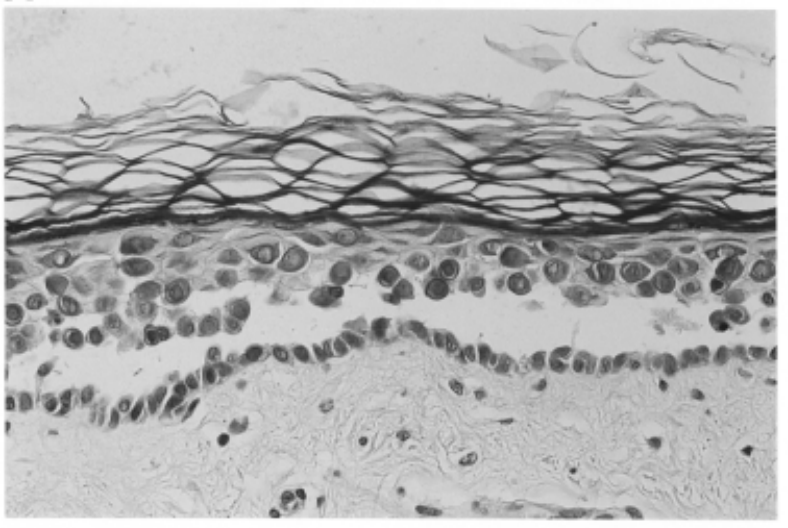

C

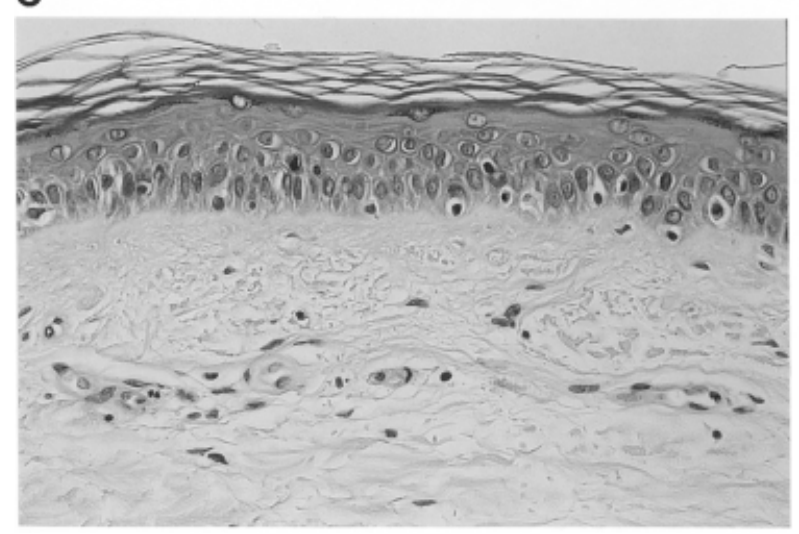

B

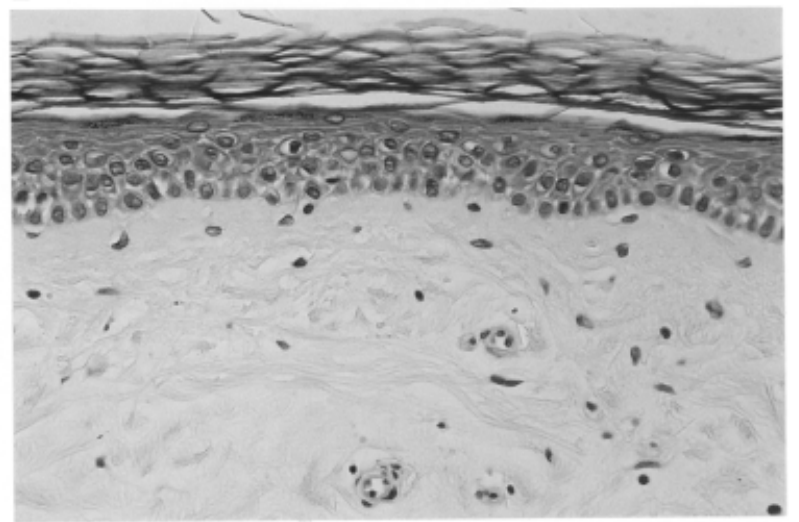

D

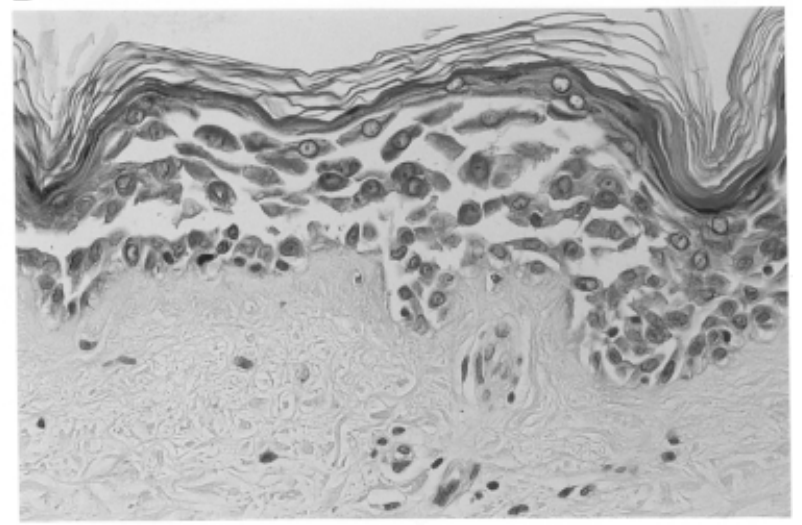

Fig. 2 Plasminogen-Mediated Acantholysis Is Inhibited by Synthetic Serine Protease Inhibitors.

Skin explants were prepared and maintained as described in the legend to Figure 1. Results of $24 \mathrm{~h}$ exposure to human plasminogen alone $(0.26 \mathrm{mg} / \mathrm{ml}$, Roche Diagnostics, Mannheim, Germany) (A) or, additionally, to $1 \mu \mathrm{g} / \mathrm{ml}(6.62 \mu \mathrm{m}) \mathrm{p}$-aminomethylbenzoic acid (B), $50 \mu \mathrm{m}$ WX-UK1 (C), or $50 \mu \mathrm{m}$ WX-UK1-D (D). The additional substances in (B)-(D) were added 150 min prior to plasminogen and were present for the whole $24 \mathrm{~h}$ of plasminogen exposure. Samples were hematoxylin- and eosin-stained. One representative of three independent experiments is shown.

(WX-374; 10-100 $\mu \mathrm{M})$ did also not prevent pemphigus vulgaris-lgG-mediated acantholysis, nor did preincubation with a tPA-neutralizing antiserum $(100 \mu \mathrm{g} / \mathrm{ml})$ or the tPA-selective synthetic active site inhibitor, tPAstop $(1.5-15 \mu \mathrm{M})$. All inhibitory substances were tested in at least three independent experiments. In the concentrations used, these substances did not produce any discernible toxicity in skin explants when applied separately (data not shown). Similar results were obtained with IgG preparations from three different donors with pemphigus 
vulgaris. Thus, various inhibitors of the plasminogen activator system failed to prevent pemphigus vulgaris IgG-induced acantholysis.

In order to rule out that this failure was due to limitations of the experimental setting, we assessed the potential of inhibitors to interfere with plasminogen-mediated acantholysis. Plasminogen is present in normal epidermis (Isseroff and Rifkin, 1983), but skin explants display a normal epidermal architecture (Figure 1B) even after prolonged incubation periods (Dobrev et al., 1996), suggesting that plasminogen is not sufficiently activated or plasminogen/plasmin is not present in sufficient amounts to cause acantholysis. However, if plasminogen is added in non-physiologically high concentrations, it enhances pemphigus IgG-induced epidermal acantholysis (Hashimoto et al., 1983) or can, by itself, produce acantholysis in skin organ culture (Morioka et al., 1987). In our experiments, the incubation of skin explants with plasminogen indeed produced marked acantholysis (Figure 2A), and this acantholysis was completely prevented by the presence of two different inhibitory agents, either $p$-aminomethylbenzoic acid $(1 \mu \mathrm{g} / \mathrm{ml}, 6.62 \mu \mathrm{M}$, Figure 2B) as previously described (Dobrev et al., 1996) or WX-UK1

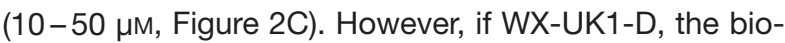
logically inactive D-enantiomer of WX-UK1, was applied along with plasminogen, there was still marked acantholysis (Figure 2D). These experiments demonstrate functional inhibition of the plasminogen activator system by the substances applied.

In our study various inhibitors of the plasminogen activator system failed to prevent pemphigus vulgaris-lgGmediated acantholysis and epidermal blistering in skin explants, whereas they effectively blocked plasminogenmediated acantholysis. We could not confirm previous reports about the prevention of pemphigus-induced acantholysis by interference with the plasminogen activator system in explant skin models using anti-uPA antibodies (Morioka et al., 1987), anti-uPAR antibodies (Xue et al., 1998), PAl-2 (Hashimoto et al., 1989) or low-molecular weight inhibitors (Naito et al., 1989; Dobrev et al., 1996). The reason for this discrepancy is not clear, but may be related to differences in the experimental setting. It seems possible that a minor effector role of the plasminogen activator system can be uncovered in a situation in which the acantholytic capacity of the autoantibodies is suboptimal. In previous studies, e.g. due to using full skin thickness preparations (Morioka et al., 1987; Hashimoto et al., 1989; Xue et al., 1998), the epidermis may have been less accessible to autoantibodies than in our situation with split skin explants. Furthermore, compared to highly purified IgG preparations used in this study, unfractioned serum (Dobrev et al., 1996) may have contained much less autoantibodies and caused less complete disruptive damage to desmosomes. Similar considerations may apply for IgG preparations from serum with lower autoantibody titers or for sera with autoantibodies of lower affinity. In addition, it cannot be excluded that if the plasminogen activator system is strong- ly activated locally, higher, and possibly toxic, doses of inhibitory substances may be required to completely inhibit plasminogen activation.

Our extensive testing of an array of inhibitors of the plasminogen activator system (Table 1) argues against the plasminogen activator system playing a major role in producing acantholysis. This view is also supported, and therapeutic approaches are further discouraged, by studies using animal models for pemphigus: (i) synthetic serine protease inhibitors failed to prevent pemphigus vulgaris IgG-induced blister formation in a neonatal mouse model (Naito et al., 1989); (ii) whereas dexamethason markedly suppressed pemphigus IgG-induced plasminogen activator activity, it did not prevent pemphigus IgG-induced blistering (Anhalt et al., 1986); (iii) desmoglein 3-deficient mice display a phenotype similar to pemphigus vulgaris patients (Koch et al., 1997), suggesting that loss of function of this desmosomal protein, either by pemphigus autoantibodies or via genetic knock out, is sufficient for acantholysis and blister formation; and (iv) most importantly, in neonatal mice deficient for either UPA or IPA, or deficient for both UPA and tPA, pemphigus IgG-induced epidermal blisters were observed to the same degree as in normal controls (Mahoney et al., 1999).

In conclusion, the data demonstrate that plasminogen activation/plasmin inhibition does not prevent pemphigus acantholysis and do not support the application of anti-plasminogen activator/plasmin strategies in the management of pemphigus.

\section{Acknowledgments}

This work was supported by the Deutsche Forschungsgemeinschaft Sonderforschungsbereich 469 (K.D., R.B.,V.M.).

\section{References}

Amagai, M. (1996). Pemphigus: autoimmunity to epidermal cell adhesion molecules. Adv. Dermatol. 11, 319-352.

Andreasen, P.A., Egelund, R. and Petersen, H.H. (2000). The plasminogen activation system in tumor growth, invasion, and metastasis. Cell. Mol. Life Sci. 57, 25-40.

Anhalt, G.J., Patel, H.P., Labib, R.S., Diaz, L.A. and Proud, D. (1986). Dexamethasone inhibits plasminogen activator activity in experimental pemphigus in vivo but does not block acantholysis. J. Immunol. 136, 113-117.

Baird, J., Lazarus, G.S., Belin, D., Vassalli, J.D., Busso, N., Gubler, P. and Jensen, P.J. (1990). MRNA for tissue-type plasminogen activator is present in lesional epidermis from patients with psoriasis, pemphigus, or bullous pemphigoid, but is not detected in normal epidermis. J. Invest. Dermatol. 95, $548-552$.

Barnett, M.L., Beutner, E.H. and Chorzelski, T.P. (1977). Organ culture studies of pemphigus antibodies. J. Invest. Dermatol. 68, 265-271.

Braungart, E., Magdolen, V. and Degitz, K. (2001). Retinoic acid upregulates the plasminogen activator system in human epidermal keratinocytes. J. Invest. Dermatol. 116, 778-784.

Dobrev, H., Popova, L. and Vlashev, D. (1996). Proteinase in- 
hibitors and pemphigus vulgaris. An in vitro and in vivo study. Arch. Dermatol. Res. 288, 648-655.

Guthaus, E., Bürgle, M., Schmiedeberg, N., Hocke, S., Eickler, A., Kramer, M.D., Sweep, C.G.J., Magdolen, V., Kessler, H. and Schmitt, M. (2002). UPA-silica-particles (SP-uPA): a novel analytical system to investigate uPA-uPAR-interaction and to test synthetic uPAR-antagonists as potential cancer therapeutics. Biol. Chem. 383, 207-216.

Hashimoto, K., Shafran, K.M., Webber, P.S., Lazarus, G.S. and Singer, K.H. (1983). Anti-cell surface pemphigus autoantibody stimulates plasminogen activator activity of human epidermal cells. J. Exp. Med. 157, 259-272.

Hashimoto, K., Wun, T.C., Baird, J., Lazarus, G.S. and Jensen, P.J. (1989). Characterization of keratinocyte plasminogen avtivator inhibitors and demonstration of the prevention of pemphigus IgG-induced acantholysis by a purified plasminogen activator inhibitor. J. Invest. Dermatol. 92, 310-314.

Isseroff, R.R. and Rifkin, D.B. (1983). Plasminogen is present in the basal layer of the epidermis. J. Invest. Dermatol. 80, 297-299.

Jensen, P.J., Baird, J., Morioka, S., Lessin, S. and Lazarus, G.S. (1988). Epidermal plasminogen activator is abnormal in cutaneous lesions. J. Invest. Dermatol. 90, 777-782.

Koch, P.J., Mahoney, M.G., Ishikawa, H., Pulkkinen, L., Uitto, J., Shultz, L., Murphy, G.F., Whitaker-Menezes, D. and Stanley, J.R. (1997). Targeted disruption of the pemphigus vulgaris antigen (desmoglein 3) gene in mice causes loss of keratinocyte cell adhesion with a phenotype similar to pemphigus vulgaris. J. Cell Biol. 137, 1091-1102.

Kramer, M.D., Schaefer, B. and Reinartz, J. (1995). Plasminogen activation by human keratinocytes: molecular pathways and cell-biological consequences. Biol. Chem. Hoppe-Seyler 376, $131-141$.

Luther, T., Magdolen, V., Albrecht, S., Kasper, M., Riemer, C., Kessler, H., Graeff, H., Muller, M. and Schmitt, M. (1997). Epitope-mapped monoclonal antibodies as tools for functional and morphological analyses of the human urokinase receptor in tumor tissue. Am. J. Pathol. 150, 1231-1244.

Mahoney, M.G., Wang, Z. and Stanley, J.R. (1999). Pemphigus vulgaris and pemphigus foliaceus antibodies are pathogenic in plasminogen activator knock out mice. J. Invest. Dermatol. 113, 22-25.

Michel, B. and Ko, C.S. (1974). Effect of pemphigus or bullous pemphigoid sera and leukocytes on normal human skin in organ cultures. An in vitro model for the study of bulous diseases. J. Invest. Dermatol. 62, 514-542.
Morioka, S., Lazarus, G.S. and Jensen, P.J. (1987). Involvement of urokinase-type plasminogen activator in acantholysis induced by pemphigus IgG. J. Invest. Dermatol. 89, 474477.

Naito, K., Morioka, S., Nakajima, S. and Ogawa, H. (1989). Proteinase inhibitors block formation of pemphigus acantholysis in experimental models of neonatal mice and skin explants: effects of synthetic and plasma proteinase inhibitors on pemphigus acantholysis. J. Invest. Dermatol. 93, 173-177.

Romer, J., Bugge, T.H., Pyke, C., Lund, L.R., Flick, M.J., Degen, J.L. and Dano, K. (1996). Impaired wound healing in mice with a disrupted plasminogen gene. Nature Med. 2, 287-292.

Schaefer, B.M., Jaeger, C.J. and Kramer, M.D. (1996). Plasminogen activator system in pemphigus vulgaris. Br. J. Dermatol. $135,726-732$.

Schmitt, M., Harbeck, N., Thomssen, C., Wilhelm, O., Magdolen, V., Reuning, U., Ulm, K., Hofler, H., Janicke, F. and Graeff, H. (1997). Clinical impact of the plasminogen activation system in tumor invasion and metastasis: prognostic relevance and target for therapy. Thromb. Haemost. 78, 285-296.

Seishima, M., Satoh, S., Nojiri, M., Osada, K. and Kitajima, Y. (1997). Pemphigus IgG induces expression of urokinase plasminogen activator receptor on the cell surface of cultured keratinocytes. J. Invest. Dermatol. 109, 650-655.

Sperl, S., Jacob, U., Arroyo De Prada, N., Stürzebecher, J., Wilhelm, O.G., Bode, W., Magdolen, V., Huber, R. and Moroder, L. (2000). (4-Aminomethyl)phenylguanidine derivatives as nonpeptic highly selective inhibitors of human urokinase. X-ray crystal structure of an UPA/inhibitor complex at $1.7 \AA$ resolution. Proc. Natl. Acad. Sci. USA 97, 5113-5118.

Sperl, S., Mueller, M.M., Wilhelm, O.G., Schmitt, M., Magdolen, V. and Moroder, L. (2001). The UPA/uPA receptor system as a target for tumor therapy. Drug News Perspect. 14, 401-411.

Stürzebecher, J., Vieweg, H., Steinmetzer, T., Schweinitz, A., Stubbs, M.T., Renatus, M. and Wilkstrom, P. (1999). 3Amidinophenylalanine-based inhibitors of urokinase. Bioorg. Med. Chem. Lett. 9, 3147-3152.

Wilkinson, J.E., Smith, C.A., Suter, M.M., Falchek, W. and Lewis, R.M. (1989). Role of plasminogen activator in pemphigus vulgaris. Am. J. Pathol. 134, 561-569.

Xue, W., Hashimoto, K. and Toi, Y. (1998). Functional involvement of urokinase-type plasminogen activator receptor in pemphigus acantholysis. J. Cutan. Pathol. 25, 469-474.

Received May 17, 2002; accepted September 2, 2002 